\title{
Subglacial floods beneath ice sheets
}

\author{
By G. W. Evatt ${ }^{1}$, A. C. Fowler ${ }^{1, *}$, C. D. Clark ${ }^{2}$ \\ AND N. R. J. Hulton ${ }^{3}$ \\ ${ }^{1}$ Mathematical Institute, Oxford University, 24-29 St Giles', \\ Oxford $O X 13 L B, U K$ \\ ${ }^{2}$ Department of Geography, University of Sheffield, Winter Street, \\ Sheffield $S 10$ 2TN, UK \\ ${ }^{3}$ School of Geosciences, University of Edinburgh, Drummond Street, \\ Edinburgh EH8 9XP, UK
}

Subglacial floods (jökulhlaups) are well documented as occurring beneath present day glaciers and ice caps. In addition, it is known that massive floods have occurred from ice-dammed lakes proximal to the Laurentide ice sheet during the last ice age, and it has been suggested that at least one such flood below the waning ice sheet was responsible for a dramatic cooling event some 8000 years ago. We propose that drainage of lakes from beneath ice sheets will generally occur in a time-periodic fashion, and that such floods can be of severe magnitude. Such hydraulic eruptions are likely to have caused severe climatic disturbances in the past, and may well do so in the future.

Keywords: jökulhlaups; ice sheets; subglacial hydrology;

Dansgaard-Oeschger events; sub-Antarctic lakes

\section{Introduction}

Jökulhlaups, or subglacial floods, occur when an ice-dammed lake drains, and the resulting discharge can be very large. Sometimes such floods occur from icemarginal lakes, and sometimes from subglacial lakes. Some of the best-known examples of jökulhlaups occur from beneath the Vatnajökull ice cap in Iceland which, sitting as it does astride the mid-Atlantic ridge, is subject to enhanced geothermal heat flow and occasional volcanic eruptions (Björnsson 1974, 1988). The outbursts from the subglacial caldera lake Grímsvötn are particularly well documented.

Floods have also been associated with ice sheets; in particular, the Channelled Scablands of Eastern Washington State in the USA are thought to have been caused by a succession (some 40 in all) of floods from the ice-dammed pro-glacial lake Missoula (Bretz 1923, 1969). These floods are thought to have been some of the largest on Earth, causing the gouged terrain that remains in place today. Similar terrain has been identified on Mars, and the apparent massive outflow

* Author for correspondence (fowler@maths.ox.ac.uk).

One contribution of 14 to a Discussion Meeting Issue 'Evolution of the Antarctic Ice Sheet: new understanding and challenges'. 
channels there have led some to suggest that Mars used to have great ice sheets which discharged huge jökulhlaups (Baker \& Milton 1974; Baker 2001; Chapman et al. 2003). There is also evidence from Antarctica of similar massive floods in the past (Sugden \& Denton 2004).

\section{(a) Dansgaard-Oeschger events}

One may ask what the climatic consequences of such floods would be. On the Earth, it is known that during the last ice age, there was a sequence of rapid climatic change events, in which the air temperature over central Greenland changed by $5-10{ }^{\circ} \mathrm{C}$ over a matter of decades (Johnsen et al. 1992; Dansgaard et al. 1993; Taylor et al. 1993). These events have been termed Dansgaard-Oeschger events, and it has been suggested that their cause was a comparable rapid change in North Atlantic Ocean circulation, itself driven by changes to the freshwater input to the North Atlantic (Stocker \& Wright 1991; Ganopolski \& Rahmstorf 2001). Essentially, the idea is that the North Atlantic circulation has different operating states: a strong, interglacial circulation and a weak, glacial circulation, each of them driven, ultimately, by the equator to pole differential solar heating. If excess fresh water is supplied to the North Atlantic, the resulting buoyancy may be sufficient to switch off a weak, glacial circulation entirely. The resulting static ocean is then so unstable that it will restart with a bang, causing the sudden warming which is observed. In all the model studies which support this view, the origin of this freshwater pulse is left unexplained, but the magnitude of the freshwater flux which is required is generally of the order of 0.1 Sverdrup $(\mathrm{Sv})$, i.e. $10^{5} \mathrm{~m}^{3} \mathrm{~s}^{-1}$. More specifically, model studies show that steady perturbations of freshwater flux to the North Atlantic of this order can cause hysteretic switches between different modes of circulation, and a sinusoidal variation of freshwater flux with amplitude of only $0.03 \mathrm{~Sv}$ over a period of 1500 years can cause model Dansgaard-Oeschger events to occur (Ganopolski \& Rahmstorf 2001).

A further suggestion is that there is a rough periodicity to the Dansgaard-Oeschger events, with the interval between them being about 1500 years (Bond et al. 1997). These events are clustered in cycles, and terminate in Heinrich events (Heinrich 1988), which are thought to occur because of massive discharge of icebergs from the Laurentide ice sheet every 10000 years or so (Bond et al. 1992; MacAyeal 1993).

If this story is true, it remains to establish the cause of the anomalous freshwater fluxes, and the reason for their apparent 1500 year periodicity. The most obvious difference between the glacial Dansgaard-Oeschger events and the present apparent lack of them (although Bond et al. (1999) suggest that they continue in muted form, for example, in the Little Ice Age) is the presence of massive land ice, particularly in North America and Europe. The most obvious source of water is from subglacial or pro-glacial lakes, and the most obvious source of periodicity is that of a jökulhlaup. Hence, we adduce to the theory of ocean circulation fluctuations the idea that there were massive outburst floods from beneath one or more of the ice sheets on the Earth at that time. 


\section{(b) Jökulhlaups}

In the absence of direct corroborative evidence for this idea, we need a viable theory which suggests that it is plausible. This theory exists, and has been frequently applied to the study of jökulhlaups. The basic theory is due to Nye (1976), who used the hydraulic theory of Röthlisberger (1972). This theory has subsequently been elaborated by a number of authors, including Spring \& Hutter (1981, 1982), Clarke (1982, 2003), Björnsson (1992) and Fowler (1999). A recent thorough review is by Roberts (2005).

The Nye theory is incredibly successful in predicting both the shape of the flood hydrograph and the flood periodicity. It has not previously been applied to the possibility of floods from beneath ice sheets, and it is the central purpose of this paper to provide a coherent application of this theory. Since our idea is that such floods should provide a robust explanation of Dansgaard-Oeschger events, we pose as goals the identification of a millennial time scale and a peak discharge of order $0.1 \mathrm{~Sv}$. It turns out that the time scale can be easily identified, but the peak discharge requires a genuine solution of the Nye model. We also examine possible floods from Lake Vostok. We show that such floods are possible and have slightly larger peak discharges than those from Grímsvötn, but the periods are much longer, being of the order of $10^{4}-10^{5}$ years.

The idea of floods from below ice sheets is not a new one. In particular, Shaw and his co-workers (Shaw 1983; Shaw et al. 1989) have been keen on positing the idea of massive subglacial floods in order to explain the origin of drumlins. The idea of floods causing subglacial landforms is also not new, and dates back to Hall (1815) - before the glacial theory! In the spirit of the times, Hall's theory was placed in a scriptural culture.

Shaw's pursuit of his thesis has been controversial: a recent defrocking is that by Clarke et al. (2005). Despite this, it has to be said that many recent discoveries are consistent with Shaw's viewpoint: the idea that the 8200 b.p. cooling was caused by a massive flood from Lake Agassiz (Alley et al. 1997; Clarke et al. 2004), the wide channel propagation of the 1996 Gjálp eruption and flood from Vatnajökull (Guðmundsson et al. 1997, 2004), the discovery of many subglacial lakes below Antarctica (Siegert et al. 1996, 2001; Siegert 2005). While not wishing to eschew imaginative possibility, in the present paper, we seek to establish possibilities that are securely based on reliable physics.

In the remainder of the paper, we provide a version of Nye's hydraulic theory which is appropriate to lakes below ice sheets, in particular, where the lake is not connected to the ice surface and the ice over the lake responds dynamically to lake level fluctuations. The resulting model is solved numerically for the case of a single lake draining to the sea, and we show that floods generally occur. For a lake beneath the Laurentide ice sheet with a large catchment area, their period can be of the order of millennia, and their peak discharge, obtained over several years, can be of the order of $0.1 \mathrm{~Sv}$. It is on the basis of these findings that we suggest that sub-ice sheet floods are a viable explanation for Dansgaard-Oeschger events. We then apply the results to the possible catatrophic drainage of Lake Vostok. The catchment for this lake is much smaller, and consequently periodic floods, if they occur, should have a period in the range $10^{4}-10^{5}$ years. 


\section{The Nye theory of subglacial floods}

\section{(a) Channel hydraulics}

The mathematical theory of jökulhlaups is given in a seminal paper by Nye (1976), based on the earlier theory of subglacial hydrology of Röthlisberger (1972). In this theory, a flood occurs by drainage from the source region, usually a lake, along a single channel. Fundamental to the concept of the theory is that the channel water pressure $p_{\mathrm{w}}$ is lower than the overburden ice pressure $p_{\mathrm{i}}$, which allows the channel to maintain its integrity and not flood the bed. This comes at a price, because the resulting positive effective pressure, defined as

$$
N=p_{\mathrm{i}}-p_{\mathrm{w}},
$$

will cause the channel to close through viscous creep of the ice. Röthlisberger's concept was that this closure could be balanced by an opening rate caused by meltback of the channel walls. The heat to cause this meltback is supplied by the viscous dissipation of the turbulent water flow in the channel.

This radical theory has been very successful in describing steady drainage, and it has proven to be equally successful in describing jökulhlaups. In Nye's formulation, the channel cross-section $S$ is thus determined by the combination of creep closure and meltback, which leads to the equation

$$
\frac{\partial S}{\partial t}=\frac{m}{\rho_{\mathrm{i}}}-K S N^{n},
$$

where $K$ is proportional to the rate coefficient $A$ in Glen's law

$$
\dot{\varepsilon}=A \tau^{n},
$$

in which $\dot{\varepsilon}$ is the second strain rate invariant, $\tau$ is the second stress invariant and $n$ is the Glen exponent. Specifically, $K=2 A / n^{n}$. The other quantities in equation (2.2) are the melt rate $m$ and the ice density $\rho_{\mathrm{i}}$. We discuss an appropriate modification of this equation below.

Equation (2.2) is derived as the kinematic condition of the ice-water interface, assuming a locally two-dimensional closure rate and, in order to obtain a closed form solution, a cylindrical channel in an infinite expanse of ice. One usually thinks of the channel as semi-circular, when the same equation will apply, provided the glacier bed is essentially stress-free. Some thought has been given to the task of modelling non-circular channels ( $\mathrm{Ng}$ 1998), but with limited success. It is possible that the semi-circular channel description is accurate during major floods, when the rapid channel opening during flood initiation is essentially isotropic.

Equations for the hydraulics of the channel are taken to be

$$
\left.\begin{array}{c}
\frac{\partial S}{\partial t}+\frac{\partial Q}{\partial x}=\frac{m}{\rho_{\mathrm{w}}}+M, \\
\operatorname{in} \alpha-\frac{\partial p_{\mathrm{w}}}{\partial x}=f \rho_{\mathrm{w}} g \frac{Q|Q|}{S^{8 / 3}} .
\end{array}\right\}
$$

These represent conservation of mass and momentum of the water flow. In them, $x$ is the distance along channel, $Q$ is the volumetric water flux, $\rho_{\mathrm{w}}$ is the density of water, $M$ is a source term to represent the inflow of tributary water from 
elsewhere on the bed; $g$ represents gravity, $\alpha$ is the local angle of inclination (downhill) of the bed and $f$ is a friction factor. Equation $(2.4)_{2}$ represents the empirical Manning law used by Nye; $f$ is related to the Manning roughness (designated $n^{\prime}$ here) by the relation

$$
f=n^{\prime 2}\left(\frac{S}{R_{\mathrm{H}}^{2}}\right)^{2 / 3}
$$

where $R_{\mathrm{H}}$ is the hydraulic radius $(=S / l$, where $l$ is the wetted perimeter). For a semi-circular channel $\left(S / R_{\mathrm{H}}^{2}\right)^{2 / 3}=\left(2(\pi+2)^{2} / \pi\right)^{2 / 3} \approx 6.6$, so that if, for example, $n^{\prime}=0.09 \mathrm{~m}^{-1 / 3} \mathrm{~s}$ (a rough channel), then $f \sim 0.05 \mathrm{~m}^{-2 / 3} \mathrm{~s}^{2}$. Clarke (2003) has queried the use of the Manning law, and in particular the high roughness coefficient. His argument stems from the idea that the high values of $n^{\prime}$ used by Nye (1976) were required because of an incorrect assumption that thermal advection in the channel flow was small. This assumption is discussed further below. A consequence of the retention of thermal advection found by Clarke (2003) is that exit water temperatures are higher than suggested by observations. To accommodate this, Clarke suggests the possibility (see also Björnsson (1992)) that heat transfer may be more effective at the very high Reynolds numbers of jökulhlaups. As we indicate below, a consequence of this suggestion is the validation of Nye's original assumption.

The momentum equation $(2.4)_{2}$ also neglects the inertia terms. Spring \& Hutter (1981, 1982) introduced these, as did Clarke (2003). Despite this, it is straightforward to show that these terms are small, and hence their inclusion suffices only to cause numerical headaches, as the problem becomes stiffer.

The energy balance for the water flow is given by

$$
\rho_{\mathrm{w}} c_{\mathrm{w}}\left[S \frac{\partial \theta_{\mathrm{w}}}{\partial t}+Q \frac{\partial \theta_{\mathrm{w}}}{\partial x}\right]=Q\left(\rho_{\mathrm{w}} g \sin \alpha-\frac{\partial p_{\mathrm{w}}}{\partial x}\right)-m\left[L+c_{\mathrm{w}}\left(\theta_{\mathrm{w}}-\theta_{\mathrm{i}}\right)\right] .
$$

Here, $\theta_{\mathrm{w}}$ is the water temperature, $\theta_{\mathrm{i}}$ is the ice temperature (which we suppose to be the pressure melting point), $c_{\mathrm{w}}$ is the specific heat of water, and $L$ is the latent heat. The first term on the right-hand side is the frictional heat generation of water flow and the second is the latent and sensible heat necessary to melt the ice wall and raise its temperature to that of the water. A final equation relates this extra heat to that supplied by turbulent heat transfer from the water, taken by Nye to be the empirical Dittus-Boelter relation (Szekely et al. 1976),

$$
a_{\mathrm{DB}}\left(\frac{\rho_{\mathrm{w}}|Q|}{\eta_{\mathrm{w}} S^{1 / 2}}\right)^{0.8} k\left(\theta_{\mathrm{w}}-\theta_{\mathrm{i}}\right)=m\left[L+c_{\mathrm{w}}\left(\theta_{\mathrm{w}}-\theta_{\mathrm{i}}\right)\right] .
$$

In this last equation, $a_{\mathrm{DB}} \approx 0.2$ is a numerical constant, $\eta_{\mathrm{w}}$ is the viscosity of water, and $k$ is its thermal conductivity. Heat transfer has been something of an issue in modelling jökulhlaups (Björnsson 1992; Clarke 2003). Use of equation (2.7) tends to give exit water temperatures which are significantly higher than the freezing point, while measurements indicate emerging floodwater is essentially at the freezing point. One simple reason for this may be that the Dittus-Boelter relation was determined by measurements at Reynolds number approximately $10^{5}$, whereas the Reynolds number is much higher in jökulhlaups, perhaps of order $10^{8}$ (Nye 1976), and it is not obvious that the Dittus-Boelter relation can be extrapolated to these higher flow rates (Björnsson 1992). A simple way of representing this 


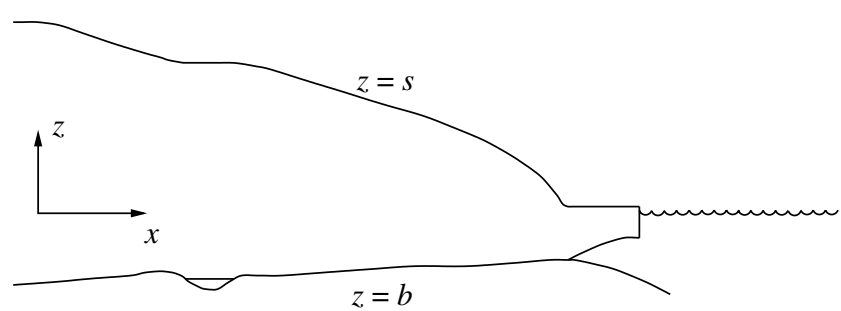

Figure 1. Schematic ice surface and bedrock topography along a hydraulic flow line from a sub-ice sheet lake.

possibility is to retain equation (2.7), but use a higher value of $a_{\mathrm{DB}}$. The five equations in (2.2), (2.4), (2.6) and (2.7) provide a sufficient model to determine the five variables $S, Q, N, m$ and $\theta_{\mathrm{w}}$, providing the other quantities in the equations are prescribed.

\section{(i) Boundary and initial conditions}

The schematic geometry of the situation we wish to consider is indicated in figure 1. We suppose an ice sheet flows over a depression in the bedrock, so that a subglacial lake exists there through entrapment of basal meltwater if the basal ice reaches the melting point, and there is net melting of water. Examples in Antarctica include Lake Vostok (Siegert 2005) and candidate lakes under the Laurentide ice sheet would be the Great Lakes, as well as Great Slave Lake and Great Bear Lake.

We consider only flow in two dimensions, with $x$ being horizontal and $z$ vertically upwards. We denote the upstream and downstream margin positions of the lake by $x_{-}$and $x_{+}$. With water flowing from left to right, there will be a volume flux $Q_{-}$at $x_{-}$into the lake and a volume flux $Q_{+}$at $x_{+}$out of the lake. (If $Q_{+}<0$ then water at $x_{+}$flows into the lake.)

The conditions we appear to require are initial conditions for $S$ and $\theta_{\mathrm{w}}$, an upstream boundary condition for $\theta_{\mathrm{w}}$ and two boundary conditions, one upstream and one downstream, for the water flux $Q$ and the effective pressure $N$. We require these conditions on each of the segments $\left[0, x_{-}\right],\left[x_{+}, l\right]$, where we locate the ice summit at $x=0$ and the ice margin at $x=l$. In figure 1 , the ice sheet margin is taken to be at the grounding line.

On the upstream segment, we have

$$
Q=0 \quad \text { at } x=0 .
$$

Because of this, the temperature equation is degenerate, and no boundary condition for $\theta_{\mathrm{w}}$ can be provided: the water temperature at the summit selects itself.

We suppose the lake is sealed from the ice surface, so that the weight of ice over the lake is supported by the water pressure. In fact, flexure of the ice will depend on the lake pressure, and the dynamics of this will determine the effective pressures at the margin. For the moment, we specify

$$
N=N_{ \pm} \quad \text { at } x=x_{ \pm},
$$

and will comment further on the choice of $N_{ \pm}$(and particularly $N_{+}$) later on. 
At the ice sheet margin, be it land-based or at an ice shelf, it is appropriate to pose

$$
N=0 \quad \text { at } x=l .
$$

In addition, we take the temperature at the inlet to the downstream channel to be that of the lake temperature, which we suppose known, thus

$$
\theta_{\mathrm{w}}=\theta_{\mathrm{L}} \quad \text { at } x=x_{+} .
$$

As the lake drains in a flood, the margin points $x_{ \pm}$may move, and their determination then forms part of the problem to be solved. One condition that is associated with this is the lake refilling equation

$$
\dot{V}=Q_{-}-Q_{+}
$$

where $V$ is the lake volume. A second condition follows from a consideration of the ice dynamics over the lake. This is discussed further below in $\$ 2 c$. In this paper, we will make the simplifying assumption that the lake roof is flat, in which case $x_{+}$and $x_{-}$are geometrically determined functions of $V$.

\section{(b) A reduced hydraulic model}

In order to provide a tractable model, we begin by non-dimensionalizing the Nye model. First, we write the hydraulic gradient in equation $(2.4)_{2}$ in terms of the effective pressure. If the bed elevation is $b$, then the bed slope is $\sin \alpha=-\partial b / \partial x$, while the cryostatic pressure at the base is $p_{\mathrm{i}}=\rho_{\mathrm{i}} g(s-b)$, where $s$ is the ice surface elevation. In terms of these, we then have that

$$
\rho_{\mathrm{w}} g \sin \alpha-\frac{\partial p_{\mathrm{w}}}{\partial x}=\Phi+\frac{\partial N}{\partial x}
$$

where the basic hydraulic potential $\Phi$ (i.e. that constructed assuming basal water pressure equals ice overburden pressure) is given by

$$
\Phi=-\frac{\partial}{\partial x}\left[\rho_{\mathrm{i}} g s+\left(\rho_{\mathrm{w}}-\rho_{\mathrm{i}}\right) g b\right] .
$$

To non-dimensionalize the model, we scale $Q$ with $Q_{0}, S$ with $S_{0}, m$ with $m_{0}$, $\theta_{\mathrm{w}}-\theta_{\mathrm{i}}$ with $\theta_{0}, t$ with $t_{0}$ and $N$ with $N_{0}$, and we choose these scales to effect suitable balances of the dominant terms in the equations. The choice of $Q_{0}$ is made to balance lake emptying rate with discharge, thus we choose

$$
Q_{0}=\frac{V_{\mathrm{L}}}{t_{0}},
$$

where $V_{\mathrm{L}}$ is a measure of total lake volume (we make this definition more precise later). The other scales can then be determined in terms of $Q_{0}$, as follows:

$$
\begin{aligned}
S_{0} & =\left(\frac{f \rho_{\mathrm{w}} g Q_{0}^{2}}{\Phi_{\mathrm{i}}}\right)^{3 / 8}, \quad m_{0}=\frac{\Phi_{\mathrm{i}} Q_{0}}{L} \\
\theta_{0} & =\frac{g h_{0}}{c_{\mathrm{w}}}, \quad t_{0}=\frac{\rho_{\mathrm{i}} S_{0}}{m_{0}}, \\
N_{0} & =\left(K t_{0}\right)^{-1 / n}
\end{aligned}
$$


in which we suppose $h_{0}$ is a representative ice thickness scale, and

$$
\Phi_{\mathrm{i}}=\frac{\rho_{\mathrm{i}} g h_{0}}{l} .
$$

Solving for $Q_{0}$, we find that the flux scale is given by

$$
Q_{0}=\left(\frac{\Phi_{\mathrm{i}} V_{\mathrm{L}}}{\rho_{\mathrm{i}} L}\right)^{4 / 3}\left(\frac{\Phi_{\mathrm{i}}}{f \rho_{\mathrm{w}} g}\right)^{1 / 2} .
$$

The dimensionless versions of the hydraulic equations are then

$$
\begin{aligned}
\frac{\partial S}{\partial t} & =m-S N^{n}, \\
\varepsilon \frac{\partial S}{\partial t}+\frac{\partial Q}{\partial x} & =\varepsilon r m+\Omega \\
\Phi+\delta \frac{\partial N}{\partial x} & =\frac{Q|Q|}{S^{8 / 3}} \\
\varepsilon S \frac{\partial \theta}{\partial t}+Q \frac{\partial \theta}{\partial x} & =Q\left[\Phi+\delta \frac{\partial N}{\partial x}\right]-m(1+\varepsilon r \theta), \\
\theta\left(\frac{|Q|}{S^{1 / 2}}\right)^{0.8} & =\gamma m(1+\varepsilon r \theta) .
\end{aligned}
$$

We non-dimensionalize surface and bed elevations $s$ and $b$ using the depth scale $h_{0}$, with the result that the dimensionless hydraulic gradient is defined by

$$
\Phi=-\frac{\partial}{\partial x}[s+\bar{\delta} b] .
$$

There are six dimensionless parameters in the model: $\varepsilon, r, \Omega, \delta, \bar{\delta}$ and $\gamma$, and these are defined, after some algebra, by

$$
\left.\begin{array}{l}
\varepsilon=\frac{g h_{0}}{L}, \quad \delta=\frac{1}{\Phi_{\mathrm{i}} l}\left[\frac{V_{\mathrm{L}}^{1 / 3}}{K}\left(\frac{\Phi_{\mathrm{i}}}{\rho_{\mathrm{i}} L}\right)^{4 / 3}\left(\frac{\Phi_{\mathrm{i}}}{f \rho_{\mathrm{w}} g}\right)^{1 / 2}\right]^{1 / n}, \\
\gamma=\frac{\rho_{\mathrm{i}} c_{\mathrm{w}}}{k a_{\mathrm{DB}} l}\left(\frac{\eta_{\mathrm{w}}}{\rho_{\mathrm{w}}}\right)^{0.8}\left(\frac{\Phi_{\mathrm{i}} V_{\mathrm{L}}}{\rho_{\mathrm{i}} L}\right)^{2 / 3}\left(\frac{\Phi_{\mathrm{i}}}{f \rho_{\mathrm{w}} g}\right)^{1 / 10}, \\
r=\frac{\rho_{\mathrm{i}}}{\rho_{\mathrm{w}}}, \quad \Omega=\frac{M l}{Q_{0}}, \quad \bar{\delta}=\frac{1}{r}-1=\frac{\rho_{\mathrm{w}}-\rho_{\mathrm{i}}}{\rho_{\mathrm{i}}} .
\end{array}\right\}
$$

In order to simplify the model, we need to estimate the sizes of these parameters. To do this, we use the values $\rho_{\mathrm{i}} \approx 0.9 \times 10^{3} \mathrm{~kg} \mathrm{~m}^{-3}, \rho_{\mathrm{w}} \approx 10^{3} \mathrm{~kg} \mathrm{~m}^{-3}$, $g \approx 9.8 \mathrm{~m} \mathrm{~s}^{-2}, \eta_{\mathrm{w}} \approx 2 \times 10^{-3} \mathrm{~kg} \mathrm{~m}^{-1} \mathrm{~s}^{-1}, k \approx 2.1 \mathrm{~W} \mathrm{~m}^{-1} \mathrm{~K}^{-1}, c_{\mathrm{w}} \approx 4.2 \mathrm{~kJ} \mathrm{~kg}^{-1} \mathrm{~K}^{-1}$, $L \approx 3.3 \times 10^{2} \mathrm{~kJ} \mathrm{~kg}^{-1}, a_{\mathrm{DB}}=0.2$ and $K=0.5 \times 10^{-24} \mathrm{~Pa}^{-n} \mathrm{~s}^{-1}$ (based on equation (2.3)) with $n=3$ and $A=6 \times 10^{-24} \mathrm{~Pa}^{-n} \mathrm{~s}^{-1}$ at $0^{\circ} \mathrm{C}$ (Paterson 1994). As discussed after equation (2.5), we estimate $f \approx 0.05 \mathrm{~m}^{-2 / 3} \mathrm{~s}^{2}$, noting that lower values (by a factor of about 5) have been advocated by Clarke (2003). Suitable choices of length and depth scales for the Antarctic ice sheet along the flow line from 
Vostok to the coast are $l=1500 \mathrm{~km}, h_{0}=3 \mathrm{~km}$, whence we find $\Phi_{\mathrm{i}}=\left(\rho_{\mathrm{i}} g h_{0} / l\right) \approx$ $18 \mathrm{~Pa} \mathrm{~m}^{-1}$, and we suppose that $V_{\mathrm{L}}=5000 \mathrm{~km}^{3}$, which is the inferred volume of Lake Vostok (Siegert 2005). For hypothetical floods of sub-Laurentide lakes, a choice of values is less certain. With Lake Ontario (volume $1600 \mathrm{~km}^{3}$ ) in mind, we use Laurentide values of $l=750 \mathrm{~km}$ and $h_{0}=1000 \mathrm{~m}$ (cf. figure 1).

Using these values (and the Vostok length scales), we then find successively (using a Glen exponent $n=3$ ) that

$$
\begin{aligned}
& Q_{0} \sim 3.8 \times 10^{6} \mathrm{~m}^{3} \mathrm{~s}^{-1}, \quad S_{0} \sim 3 \times 10^{5} \mathrm{~m}^{2}, \quad m_{0} \sim 201 \mathrm{~kg} \mathrm{~m}^{-1} \mathrm{~s}^{-1}, \\
& \theta_{0} \sim 7.0 \mathrm{~K}, \quad t_{0} \sim 1.3 \times 10^{6} \mathrm{~s}(0.04 \mathrm{yr}), \quad N_{0} \sim 1.1 \times 10^{6} \mathrm{~Pa}(11 \mathrm{bar}),
\end{aligned}
$$

and the dimensionless parameters are of typical sizes

$$
\gamma \sim 0.53, \quad \varepsilon \sim 0.09, \quad r \sim 0.9, \quad \bar{\delta} \sim 0.1, \quad \delta \sim 0.04, \quad \Omega \sim 1.3 \times 10^{-5} .
$$

The value of $\Omega$ is based on the assumption that base flow rate of the outlet stream from Vostok is $M l \mathrm{~m}^{3} \mathrm{~s}^{-1}$, and that this is equal to the product of the average basal melt rate and the catchment area for the Vostok stream.

We calculate the catchment areas below the ice sheet which will drain into Lake Vostok and into the Vostok stream based on a simple analysis of the Bedmap dataset (Lythe et al. 2001). We use ice thickness and bed elevation values to calculate hydraulic potential at the bed assuming that basal water pressure is ubiquitously at ice overburden pressure. We then derive flow paths across the hydraulic surface for the whole domain using ArcInfo GIS software. Based on this analysis, we calculate the 'upstream' area of the subglacial basin that would feed water in to Lake Vostok across these potentials, that is, we calculate the size of the area in which all the hydraulic flow paths lead into the lake, and we do the same for the hydraulic flow paths into the Vostok stream, which itself is a hydraulic grade line from Vostok to the coast. On this basis, we compute the catchment for Lake Vostok to be $28000 \mathrm{~km}^{2}$ and the catchment to the Vostok stream to be $765000 \mathrm{~km}^{2}$.

To compute the basal melt rate $w_{\mathrm{m}}$, we use the formula

$$
w_{\mathrm{m}}=\frac{G+\tau_{\mathrm{b}} u_{\mathrm{b}}+k \frac{\partial T}{\partial z}}{\rho_{\mathrm{i}} L},
$$

where $G$ is geothermal heat flux, $\tau_{\mathrm{b}}$ is basal shear stress, $u_{\mathrm{b}}$ is basal sliding velocity, $k$ is thermal conductivity, $\partial T / \partial z$ is the basal vertical temperature gradient, $\rho_{\mathrm{i}}$ is ice density, and $L$ is latent heat. We use values $G=65 \mathrm{~mW} \mathrm{~m}^{-1}$, $\tau_{\mathrm{b}}=0.1 \mathrm{bar}, \quad u_{\mathrm{b}}=100 \mathrm{~m} \mathrm{yr}^{-1}, \quad k=2.1 \mathrm{~W} \mathrm{~m}^{-1} \mathrm{~K}^{-1}, \quad \rho_{\mathrm{i}}=900 \mathrm{~kg} \mathrm{~m}^{-3}, \quad L=3.3 \times$ $10^{5} \mathrm{~J} \mathrm{~kg}^{-1}, \partial T / \partial z=-1.6 \times 10^{-2} \phi \mathrm{K} \mathrm{m}^{-1}$, based on a surface to base temperature difference of $50 \mathrm{~K}$ and a depth of $3000 \mathrm{~m}$. The quantity $\phi$ is an enhancement factor which is one for pure (steady) conduction, but greater than one when advection is important. In accordance with thermal boundary layer theory, its size should be $\phi \sim \sqrt{P e}$, where the reduced Péclet number $P e$ is given by $P e=u_{b} h_{0}^{2} / \kappa l$, and using previous values together with a value for the thermal diffusivity $\kappa=38 \mathrm{~m}^{2} \mathrm{yr}^{-1}$, we find $\sqrt{P e} \sim 4$. This is of course an upper bound. Substituting these values into equation (2.24), the constituent terms are a geothermal melt rate approximately $6.5 \mathrm{~mm} \mathrm{yr}^{-1}$, a frictional melt rate approximately $3 \mathrm{~mm} \mathrm{yr}^{-1}$ and a thermal freezing rate in the range 
3.5-14.5 $\mathrm{mm} \mathrm{yr}^{-1}$, although if the ice at the base becomes temperate, this freezing rate drops to zero. A plausible range for melt rate is thus $0-10 \mathrm{~mm} \mathrm{yr}^{-1}$, with the effect of advective cooling suggesting a low estimate within this range. If, for example, the basal melt rate is $2 \mathrm{~mm} \mathrm{yr}^{-1}$, then the normal Vostok stream discharge is $1.5 \times 10^{9} \mathrm{~m}^{3} \mathrm{yr}^{-1}$ or $M l=48 \mathrm{~m}^{3} \mathrm{~s}^{-1}$.

\section{(i) Simplified hydraulics}

The parameters $\varepsilon, \bar{\delta}, \delta$ and $\Omega$ are all relatively small, and we seek to ignore these where possible. An appropriate simplification was considered by Fowler (1999), who showed that the Nye model had solutions representing periodic jökulhlaups.

The neglect of $\varepsilon$ is a regular perturbation (there is of course a rapid transient associated with the initial condition for $\theta$, but this is not of concern), and we may safely put $\varepsilon=0$. We cannot, however, neglect the very small tributary flux term $\Omega$, because this term allows for the presence of a seal in between floods, as discussed later.

The temperature equation requires some discussion, partly because the effect of temperature has sometimes been ignored (Fowler 1999), although it can play an important part in quantitative solutions (Spring \& Hutter 1981). Equation $(2.19)_{5}$ really defines $m$; substituting this in equation $(2.19)_{4}$, neglecting the term in $\varepsilon$ and using $(2.19)_{3}$, we have

$$
\gamma Q \frac{\partial \theta}{\partial x}=\gamma Q\left[\Phi+\delta \frac{\partial N}{\partial x}\right]-\theta\left(\frac{|Q|}{S^{1 / 2}}\right)^{0.8} .
$$

We can see from this that $\theta$ relaxes to $O\left(\gamma|Q|^{0.2} S^{0.4}\right)$ exponentially on a length scale of $O\left(\gamma|Q|^{0.2} S^{0.4}\right)$. Between floods, this distance is really very small as is the dimensionless temperature, and it is reasonable to suppose $\theta \approx 0$. During a flood, the equation above suggests that $\theta_{x} \sim O(1)$ (where here and subsequently, $x$ and (later) $X$ subscripts denote partial derivatives) over a distance $\sim O\left(\gamma|Q|^{0.2} S^{0.4}\right)$, and as a consequence the melting rate

$$
m \approx \frac{|Q|^{3}}{S^{8 / 3}}-Q \theta_{x}
$$

will depend significantly on the water temperature, unless (discussed later) $\gamma|Q|^{0.2} S^{0.4} \ll \delta$.

The small coefficient $\delta$ represents a singular perturbation and cannot be neglected in the vicinity of the lake. In fact, since the presence of a lake indicates a local hydraulic minimum, we must have $\Phi<0$ near the lake, so that neglect of the term in $\delta$ in the momentum equation would imply $Q<0$, and the lake would never drain. Floods occur in this theory because of the existence of a seal, which allows backflow towards the lake. The position of the seal migrates slowly backwards towards the lake, and a flood is then initiated when it reaches the lake. Hydraulically, the lake overflows.

Away from the lake (where $\Phi>0$ ), the limits $\delta \rightarrow 0, \varepsilon \rightarrow 0$ and $\Omega \rightarrow 0$ allow an outer solution in which $Q \approx Q(t), m \approx Q\left(\Phi-\theta_{x}\right)$ and $N, Q$ and $S$ are related by

$$
\left.\begin{array}{rl}
\frac{\partial S}{\partial t} & =Q\left(\Phi-\theta_{x}\right)-S N^{n}, \\
Q & =\Phi^{1 / 2} S^{4 / 3} .
\end{array}\right\}
$$


The value of $Q(t)$ is determined by matching this approximation to the flow near the lake, in which we cannot neglect the small term in $\delta$. Specifically, we rescale the space coordinate as

$$
x=x_{+}+\delta X
$$

so that

$$
\left.\begin{array}{rl}
\Phi+\frac{\partial N}{\partial X} & =\frac{Q|Q|}{S^{8 / 3}}, \\
Q & =\omega\left(X-X^{*}\right),
\end{array}\right\}
$$

where

$$
\omega=\delta \Omega .
$$

The unknown $X^{*}(t)$ marks the position of the seal. When it is positive, the lake is impounded, and gradually fills because of inflow at $x_{-}$. As long as $X^{*}$ remains positive, channel outflow at the ice margin is small, but as soon as $X^{*}$ reaches zero, a flood is initiated, and the lake will drain. The 'hydraulic' length scale $\delta l$ is about $135 \mathrm{~km}$, comparable to dimensions of Lake Vostok, and we will generally suppose that $\Phi$ also varies on this hydraulic length scale near the lake, but varies more slowly away from the lake. Thus, we suppose that as $X$ becomes large away from the lake, $\Phi \approx \Phi_{+}$, and is constant. In this case, given $S$, suitable conditions for $N$ in equation (2.29) are

$$
\left.\begin{array}{c}
N=N_{+}(t) \quad \text { on } X=0, \\
\frac{\partial N}{\partial X} \rightarrow 0 \quad \text { as } X \rightarrow \infty .
\end{array}\right\}
$$

The prescription of the marginal effective pressure $N_{+}(t)$ will be discussed later. The second condition as $X \rightarrow \infty$ is a matching condition which ensures that the solution near the lake blends smoothly with the outer solution far from the lake. The extra condition on $N$ thus determines $Q(t)$ in the outer solution as we suppose, and it is this which determines the seal position $X^{*}$. From equation $(2.19)_{4}$, we have (neglecting terms of $O(\varepsilon)) m \approx Q\left[\Phi+N_{X}-\Theta_{X}\right]$, where we define $\Theta=\theta / \delta$, and thus $S$ is stepped forward by solving

$$
\frac{\partial S}{\partial t}-\frac{\dot{x}_{+}}{\delta} \frac{\partial S}{\partial X}=Q\left[\Phi+N_{X}-\Theta_{X}\right]-S N^{n}
$$

where $\Theta$ satisfies

$$
\Theta_{X}=\Phi+N_{X}-\left(\frac{\delta}{\gamma Q^{0.2} S^{0.4}}\right) \Theta
$$

if $Q>0$, and then

$$
\Theta=0 \quad \text { at } X=0,
$$

assuming the lake temperature to be at the melting point. We suppose that $\Theta=0$ if $Q<0$.

The extra term, $\left(\dot{x}_{+} / \delta\right)(\partial S / \partial X)$, arises because of the change of variable (2.28). It is negligible between floods. Numerically, it is irrelevant, because even if we allow the lake margin to move, we solve the hydraulic equations on a fixed grid, allowing the inlet portal to migrate along this grid. 


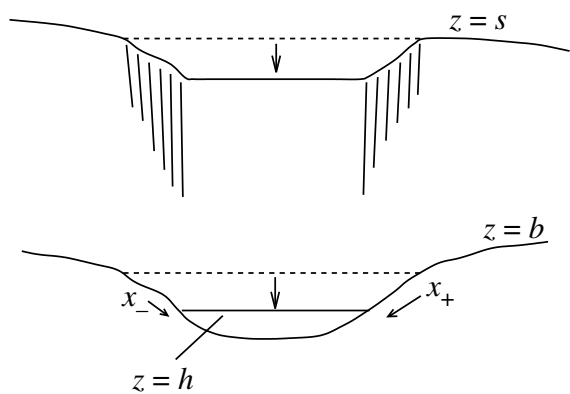

Figure 2. A schematic representation of the collapsing ice cauldron over the lake. The dotted lines indicate pre-flood positions of ice surface and lake roof. As a flood progresses, the lake roof subsides causing collapse of the ice surface. If this is sufficiently rapid, the marginal ice will rupture, allowing the central ice cauldron to sink passively. This is indicated on the diagram by the vertical (ring) fractures.

\section{(c) Ice sheet flow and portal mechanics}

In a previous study of Grímsvötn (Fowler 1999), the hydraulic model was selfcontained. The physical basis of this model was the idea that the ice cover was broken at the caldera walls, thus allowing the lake to be open to the atmosphere, as is sometimes observed (Björnsson 1988). As a consequence, lake volume (and thus discharge) were directly related to the marginal effective pressure.

For sub-ice sheet lakes, we do not expect the water to be exposed in this way, and a proper consideration of the boundary condition for the lake discharge requires a further analysis of the over-lake ice dynamics. Figure 2 shows a cartoon view of the possible evolution of the ice surface during a flood. As the lake discharges, the ice is drawn down, and this requires an underpressure in the lake so that the ice can deform. If the aspect ratio of the over-lake ice shelf is large, then the appropriate approximate theory to describe this deformation is the viscous analogue of beam theory (Howell 1994). Viscous beam theory provides a relation between the surface velocity $w$ and the effective pressure $N$. If, as shown, the ice and lake surfaces remain flat in the interior, then the surface deformation rate $w=s_{\mathrm{t}}=h_{\mathrm{t}}$ over the lake, where $z=h$ denotes the lake roof, and

$$
\dot{V}=A_{\mathrm{L}} h_{\mathrm{t}},
$$

where $A_{\mathrm{L}}$ is the lake roof area, a geometrically determined function of $h$. The relation between $N$ and $w$ provides a generalized version of the lake refilling equation which has been used in previous studies. A possible complication is that for the large floods with which we are concerned, the vertical collapse may be hundreds of metres in a matter of years. The stresses necessary to produce such rapid collapse may be much larger than the fracture strength of ice, and as a consequence, the ice may fracture near the lake margin. As collapse continues, a series of such ring fractures will form, allowing the central part of the ice to collapse passively, as indicated in figure 2. Such ring fractures are commonly seen on small ice cauldrons on Vatnajökull (e.g. Guðmundsson et al. 1997, 2004). 
We will not provide the viscous beam theory here, although it has been done and will be reported elsewhere. A consequence of the analysis is that the open lake assumption still appears to be reasonable. In this case, we could suppose that the lake margin positions $x_{+}$and $x_{-}$remain fixed. Additionally, we suppose that as the lake empties, the marginal ice collapses or fractures in such a way that the collapsed ice blocks in the lake do not provide much resistance to the water draining towards the outlet portal (cf. figure 2). The interior lake water has the uniform dimensional pressure $\rho_{\mathrm{i}} g(s-h)$ (as it did initially) assuming the lake roof is flat, and is in hydrostatic equilibrium with the water at the portal entrance. It follows from this that at $x=x_{+}$, where the elevation of the lake roof is $h_{+}$, the dimensional effective pressure is

$$
N=\rho_{\mathrm{w}} g\left(h_{+}-h\right),
$$

and hence from equation (2.35),

$$
\frac{\partial N}{\partial t}=\frac{\rho_{\mathrm{w}} g\left(Q_{+}-Q_{-}\right)}{A_{\mathrm{L}}} .
$$

This is the version of the lake refilling equation that is normally used. By our choice of volume flux scale, this can be written in the dimensionless form

$$
\frac{\partial N}{\partial t}=\frac{Q_{+}-\nu}{A_{\mathrm{L}}},
$$

where $A_{\mathrm{L}}$ now represents dimensionless lake area (scaled with a typical value $A_{0}$, for example that when full under basic hydraulic conditions), and we have chosen a lake depth scale $h_{\mathrm{L}}$ to be

$$
h_{\mathrm{L}}=\frac{N_{0}}{\rho_{\mathrm{w}} g} .
$$

$h_{\mathrm{L}}$ is, in fact, the order of magnitude of the drawdown of the lake during a flood. Thus, the 'typical' lake volume change during a flood is

$$
V_{\mathrm{L}}=A_{0} h_{\mathrm{L}} \text {. }
$$

A lake will empty during a flood if its volume is less than $V_{\mathrm{L}}$ (approximately, since $V_{\mathrm{L}}$ is simply a scale).

The parameter $\nu$ is then defined by

$$
\nu=\frac{Q_{-}}{Q_{0}} ;
$$

$\nu$ is the dimensionless inflow rate, which we take to be constant (and small). For $N_{0} \sim 10$ bar, we have $h_{\mathrm{L}} \sim 100 \mathrm{~m}$. This definition of $V_{\mathrm{L}}$ allows us to talk sensibly about volume changes in an infinitely deep lake, in which floods will occur but the lake will not empty.

We call the above model a Grímsvötn type model. An alternative supposition, which we call a Vostok type model, is that as the marginal ice blocks collapse, there is severe impedance of the flow, and the channel must melt its way back with the lake margin. In this case, $x_{+}$varies and we apply

$$
N_{+}=0 \quad \text { at } x=x_{+} .
$$


As the lake discharges, we suppose that the central part of the over-lake ice remains flat, so that $x_{+}$(and $x_{-}$) are determined kinematically in terms of lake volume. In order to solve equation (2.32) for the channel cross-section, we assume that $S$ is continuously differentiable at $x_{+}$.

\section{(i) Ice sheet flow}

Another consideration of importance is the recovery of the ice sheet between floods. The drawdown of the over-lake ice causes the ice to flow back in towards the lake, and in the (Vostok) case of a moving ice margin, it is this drawdown which causes the seal to reform, since it provides a basic hydraulic gradient back towards the lake. We have examined two ways of modelling the ice sheet flow. One is to take an isothermal shallow ice flow model (e.g. Hindmarsh 2001), which takes the form of a nonlinear diffusion equation. This model uses Glen's flow law together with the shallow ice approximation (Fowler \& Larson 1978).

A simpler model for the ice flow assumes perfect plasticity (Nye 1951; Van der Veen 1999), when the ice is assumed to be shallow and perfectly plastic with a prescribed yield stress. In both models, the ice flow is suspended while a flood occurs, and the ice sheet is allowed to draw down kinematically as illustrated in figure 2. We have not found any serious differences between models in which either plastic or viscous ice flow is included.

\section{(ii) Portal closure}

A feature of the Vostok type portal model is that $N=0$ at the channel entrance. According to the Nye model (2.2), this allows indefinite growth of the channel cross-section there. Some further consideration of the reason for this is necessary.

Nye (1976) based his closure equation on Röthlisberger's (1972) earlier use of his borehole closure theory (Nye 1953). This assumes a circular void in an infinite expanse of ice. It is easy to modify this theory (Evatt in preparation) to allow for an externally imposed pressure at a finite distance, and even (with some licence) to allow an external surface at finite distance having no stress, but with a radial body force mimicking gravity. These two problems give similar results, and remove the unbounded growth that occurs in equation (2.2) when $N=0$. The modification which this leads to can be written in the form

$$
\frac{\partial S}{\partial t}=\frac{m}{\rho_{\mathrm{i}}}-\frac{K S N^{n}}{\left(1-\frac{S}{S_{\mathrm{f}}}\right)^{n}},
$$

where $S_{\mathrm{f}}$ is the finite area of the enclosing circular ice. The dimensionless version (2.32) is modified to

$$
\frac{\partial S}{\partial t}=Q\left[\Phi+N_{X}-\Theta_{X}\right]-\frac{S N^{n}}{\left(1-\frac{S}{S_{\mathrm{f}}}\right)^{n}},
$$

where we have scaled $S_{\mathrm{f}}$ with $S_{0}$. The point now is that opening will indeed occur if $S<S_{\mathrm{f}}$, but when $S$ reaches $S_{\mathrm{f}}$, it remains there. 


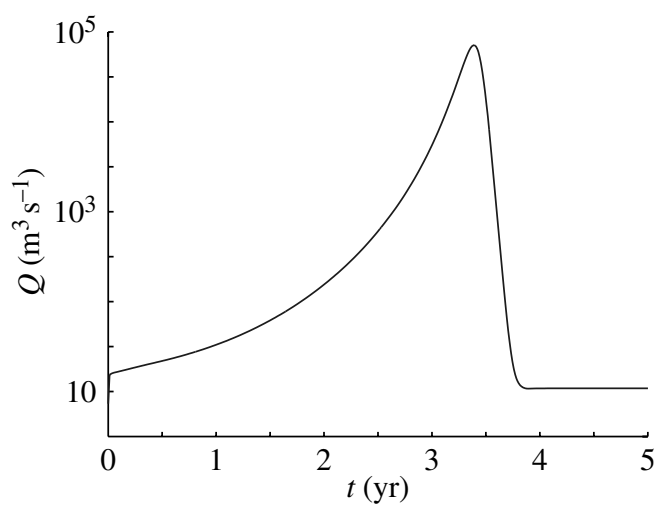

Figure 3. Hydrograph of a flood from a lake such as Lake Vostok. The lake is taken to be of depth $500 \mathrm{~m}$, width $50 \mathrm{~km}$ and length $240 \mathrm{~km}$, sitting in a Gaussian depression on an otherwise flat bed, slightly tilted upwards in the direction of ice flow. This computation uses a fixed margin and the lake refilling equation (2.38). The equations (2.29) and (2.32) are solved with $\dot{x}_{+}=0, \Theta_{X}=0$, and the parameters used are $\nu=0.5 \times 10^{-6}, \omega=0.5 \times 10^{-6}$, with discharge and time scales $Q_{0}=3.8 \times 10^{6} \mathrm{~m}^{3} \mathrm{~s}^{-1}, t_{0}=0.04 \mathrm{yr}=15$ days. The value of $\nu$ is immaterial to the shape of the hydrograph. The peak discharge is about $10^{5} \mathrm{~m}^{3} \mathrm{~s}^{-1}$ and the total discharge is some $6 \times 10^{11} \mathrm{~m}^{3}$. The duration of the flood is about 18 months.

\section{Numerical results}

It can be seen that there is a variety of ways in which we can choose to include ice dynamics and portal conditions in the model. We have implemented different versions of these, and conclude that the behaviour of the model is essentially similar no matter what choice we make. The exception to this statement is the effect of temperature, where the inclusion of the advective term, $\Theta_{X}$, in equation (2.32) can have a significant effect on flood discharge, if $\gamma$ is not small. We do not report any results here in which the effects of thermal advection are included, ostensibly on the basis that the parameter $\gamma$ in equation (2.33) is small.

\section{(a) Flood magnitude and frequency}

Figure 3 shows the hydrograph of a typical flood from a sub-ice sheet lake resembling Lake Vostok. As we have commonly found to be the case for hypothetical subglacial lakes of such large magnitude, the floods are very large, and occur periodically with a very long period. As we discuss later, the period is essentially controlled by the rate at which the lake is refilled, and for the case of Vostok, the period may be of the order of 40000 years, or even longer. The long period is due to the relatively small $\left(28000 \mathrm{~km}^{2}\right)$ catchment area of the lake. The peak discharge is about $10^{5} \mathrm{~m}^{3} \mathrm{~s}^{-1}$, and the total discharge is some $6 \times 10^{11} \mathrm{~m}^{3}$. In this simulation, the lake does not empty. With the current configuration of the ice sheet, the drainage path is expected to lie in the direction of Byrd Glacier in the Transantarctic Mountains. Figure 4 shows the present day hydraulic drainage paths, and figure 5 shows the ice surface and bed along the hydraulic flow line from Vostok. 


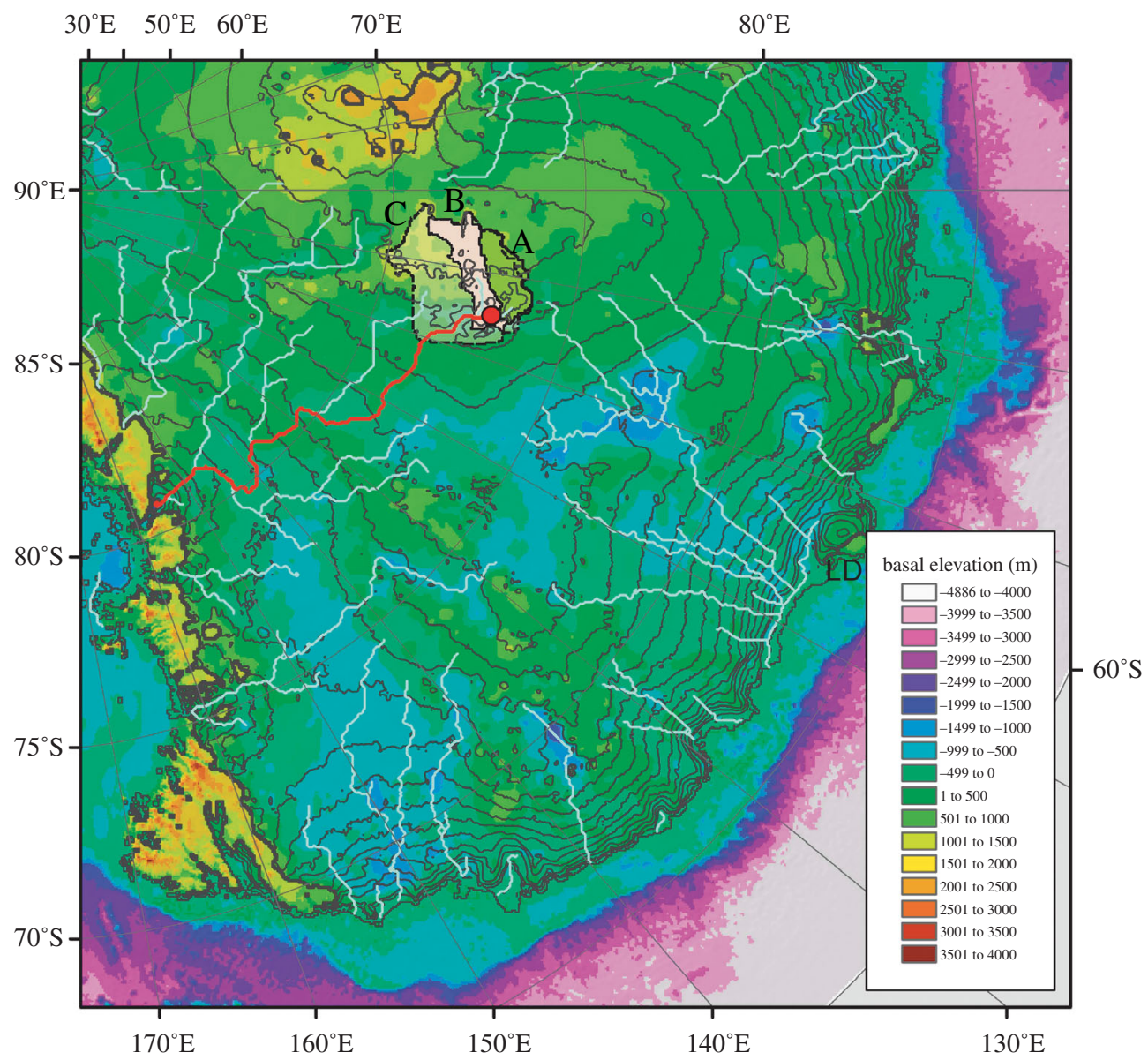

Figure 4. Major hydraulic flow paths (in white) under Antarctica assuming water pressure equals ice overburden pressure, calculated using present-day ice surface elevation and bed elevation (shown as colour shading). See text for further details. Hydraulic contours (in grey) are in metres of water equivalent. The present day path from Lake Vostok (marked as a red dot) leads to the Transantarctic Mountains and is shown in red. The green polygon labelled (A), is the area currently draining directly into Lake Vostok, above the main lake spillway, with the pink polygon (B) being an additional area that also drains back into the lake under normal conditions. The yellow polygon (C), corresponds to a further area that we suppose might also drain into Vostok with an slightly expanded ice sheet, such as could occur with lowered glacial sea levels. Law Dome, which provides an alternative outlet under a larger ice sheet, is marked LD on the coast at the top left of the inset.

The principal distinction between the simulated floods from a Laurentidetype lake (we use Lake Ontario as a representative) and a Vostok-type lake is in the assumed size of the catchment area. The basic hydraulic gradient is similar, but we suppose the catchment for Lake Ontario is much larger. Its current sub-aerial catchment is $64000 \mathrm{~km}^{2}$, and under an ice sheet this is likely to be larger, since the ice surface would have sloped towards Lake Ontario from some distance, and the basal topography is quite flat. We have used a value of $450000 \mathrm{~km}^{2}$. This value was computed by analysing the 


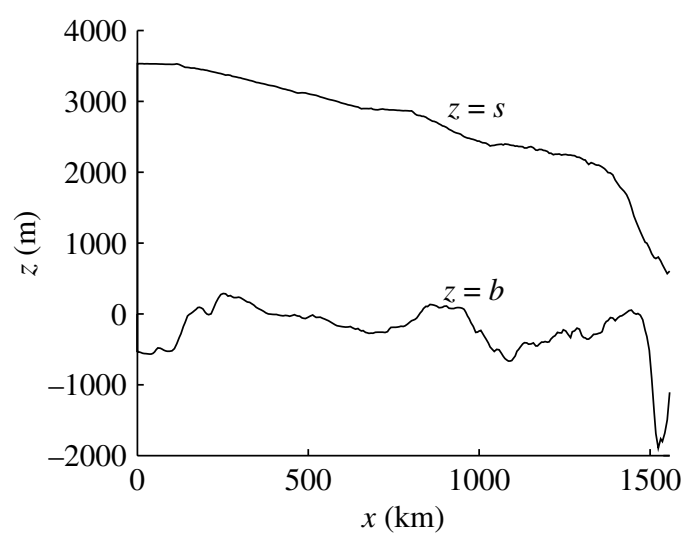

Figure 5. Ice surface and bedrock topography along the hydraulic flow line from Lake Vostok in Antarctica shown in figure 4. See text for further details. The deep trough at the right is the underdeepening under the Byrd Glacier.

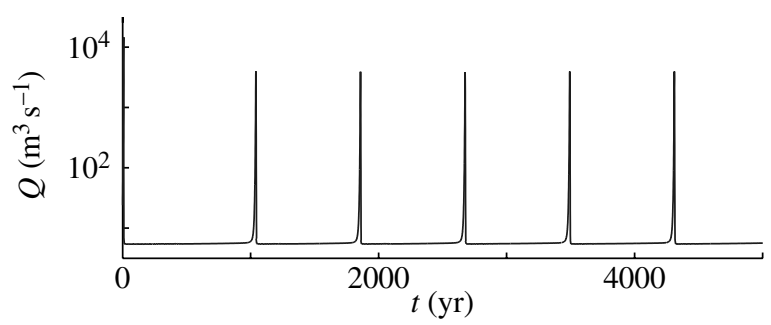

Figure 6. A sequence of jökulhlaups from a Laurentide type lake. The lake is taken to be of depth $110 \mathrm{~m}$, width $100 \mathrm{~km}$ and length $200 \mathrm{~km}$, sitting in a Gaussian depression on an otherwise flat bed, slightly tilted upwards in the direction of ice flow. This computation uses a moving margin at which $N=0$. The equations (2.29) and (2.44) are solved with $\Theta_{X}=0$ and we prescribe $S_{\mathrm{f}}=\pi(s-b)^{2}$. The ice sheet deforms plastically between floods with a yield stress of $8000 \mathrm{~Pa}$. (This low value is chosen in order to obtain an over-lake ice depth of the order of $1000 \mathrm{~m}$.) The parameters used are $\nu=0.74 \times 10^{-4}, \omega=0.72 \times 10^{-5}$, with discharge and time scales $Q_{0}=1.9 \times 10^{5} \mathrm{~m}^{3} \mathrm{~s}^{-1}, t_{0}=0.26 \mathrm{yr}=95$ days. The peak discharge is about $4 \times 10^{3} \mathrm{~m}^{3} \mathrm{~s}^{-1}$, and the period is some 800 years.

upstream contributing area of the hydropotential surface that should feed water to subglacial Lake Ontario. We take this as a typical value, while recognizing that for different lakes there will be a good deal of variation around this figure.

The result of the larger catchment is that the period is much shorter, some 800 years. The magnitude of the peak discharge is smaller, but the floods are of longer duration, some 10 years, as opposed to the year long floods from the Vostok type lake, and the total discharge is similar, about $4 \times 10^{11} \mathrm{~m}^{3}$. Figure 6 shows a sequence of these floods, which appear as spikes because of the brevity of the floods relative to the period. Figure 7 shows the detail of the hydrograph of one of these floods. 


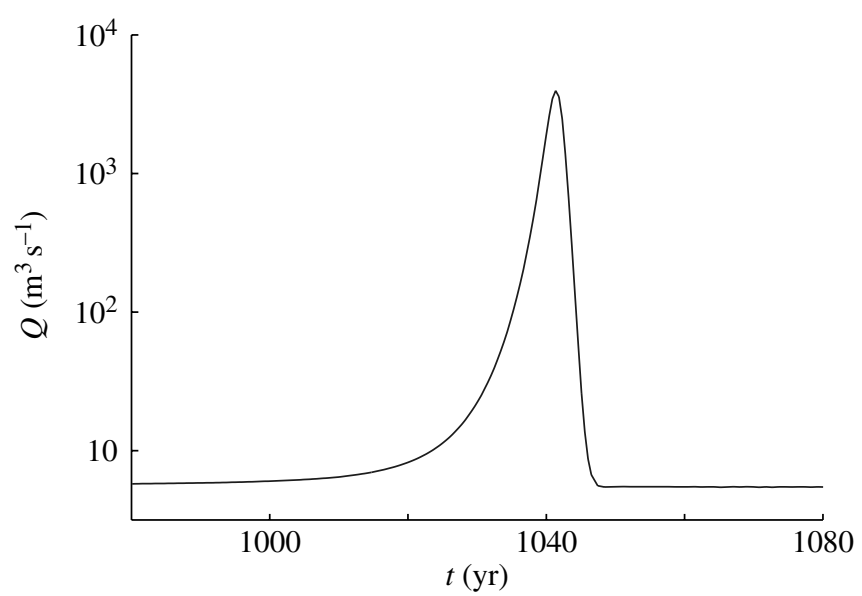

Figure 7. Hydrograph from a Laurentide flood, parameters as in figure 6 . The total discharge is some $4 \times 10^{11} \mathrm{~m}^{3} \mathrm{~s}^{-1}$, and the flood duration is about 10 years.

\section{Discussion}

In our numerical studies of drainage from sub-ice sheet lakes, we have found that periodic flooding is the normal drainage mechanism, and this seems to be the usual case when the parameter $\omega$ is small. The magnitude and duration of the floods appear to be controlled by the channel hydraulics, but the peak discharge is essentially related to the lake volume; big lakes produce big floods. A question of interest is whether lakes will be emptied during a flood. This depends on the depth of the lake. In fact the drawdown during a flood is given by the quantity $h_{\mathrm{L}}$ in equation (2.39), so that a first-order estimate for total flood discharge is

$$
V_{\mathrm{L}}=\frac{A_{\mathrm{L}} N_{0}}{\rho_{\mathrm{w}} g},
$$

where $A_{\mathrm{L}}$ is lake area and $N_{0}$ is effective pressure level in the channel. Incidentally, this suggests that the small floods apparently observed by Wingham et al. (2006) are associated with drainage through channels at low effective pressure.

The interval between floods is, fairly obviously, controlled by the refilling rate. This interval is simply the total flood discharge divided by the refilling rate, which itself is the product of the basal melt rate and the catchment area; thus a simple estimate for the period is just

$$
P \approx \frac{V_{\mathrm{L}}}{m_{\mathrm{B}} A_{\mathrm{C}}}=\frac{N_{0} A_{\mathrm{L}}}{\rho_{\mathrm{w}} g m_{\mathrm{B}} A_{\mathrm{C}}},
$$

where $A_{\mathrm{C}}$ is lake catchment area and $m_{\mathrm{B}}$ is basal melt rate. A small catchment, such as is thought to be appropriate for Vostok, leads to periods of tens of thousands of years. If we take $V_{\mathrm{L}} \approx 6 \times 10^{11} \mathrm{~m}^{3}, A_{\mathrm{C}}=28000 \mathrm{~km}^{2}$, then a basal melt rate in the range $1-4 \mathrm{~mm} \mathrm{yr}^{-1}$ yields estimates for periodic discharge between 5000 and 21000 years. However, we have also modelled flow paths during ice maximum conditions such as might result from lowered sea levels during glacial periods. The rearrangement of the ice surface under such 
conditions leads to water being forced in the direction of Law Dome, and a roughly fourfold extension of the Vostok basin to about $110000 \mathrm{~km}^{2}$ (see figure 4). Under such conditions, refilling rates and flood frequencies would be likely to decrease accordingly. The larger catchments, which may also apply to putative Laurentide lakes, give shorter periods, but equally large total discharges.

An issue which we have not addressed, but which we must at least mention, concerns the rôle of melting and refreezing of the lake roof ice. In our discussion of the basal drainage system from the lake, we have assumed that inflow to and outflow from the lake are entirely due to supply and removal. In general, this is unlikely to be true, and a further source or sink is that due to melting or refreezing of the roof ice over the lake; indeed, this is known to be a dominant thermal process under ice shelves (Jenkins 1991; Holland \& Jenkins 1999). A simple calculation of a Rayleigh number for a lake of depth $100 \mathrm{~m}$ subject to a geothermal heat flux of $50 \mathrm{~mW} \mathrm{~m}^{-2}$ gives a value of $6 \times 10^{7}$, so that thermal convection is inevitably vigorous, and melting and refreezing can be expected; indeed, this is known to occur under subglacial lakes Vostok and Concordia (Siegert 2005; Tikku et al. 2005). It is clear that a considered view of flood periodicity and magnitude requires an understanding of rates of subglacial melting and refreezing, and it is also clear that theoretical assessment of this process is of some difficulty.

\section{Conclusions}

Our central finding is that lakes below ice sheets will normally drain by flooding. The floods can be of large magnitude, may empty the lake, and occur at periods, which are of the order of the lake volume divided by the lake refilling rate. The refilling rate is (if we ignore melting and refreezing at the lake roof) simply the catchment area for the lake multiplied by the basal melt rate. This principally varies with the catchment area. For a central lake such as Vostok, the catchment area is relatively small, and the estimated period is of the order of $10^{4}$ years (it should be emphasized that this is a crude estimate).

As well as the present theoretical suggestion of massive floods from subAntarctic lakes, there is direct geomorphological evidence for their occurrence (Denton \& Sugden 2005), there is direct observation of outlet floods occurring from Antarctic subglacially derived meltwater ponds (Goodwin 1988), and there is recent observation of rapid ice surface elevation changes which essentially imply internal subglacial flooding (Wingham et al. 2006).

Antarctica has mountainous basal terrain, and is littered with many small subglacial lakes (Siegert 2005). We conceive of the possibility that drainage from below the ice sheet occurs by many episodic drainage events, so that the basal drainage system resembles that of a Darcian flow in a porous medium, on a grand scale. As the lakes drain, the ice sheet surface will pump up and down, and on the time scale of the drainage events, the surface will display the appearance of a pan of bubbling milk.

If we shift our attention to the former Laurentide ice sheet, it is natural to enquire whether similar floods could have occurred there. Evidence for floods associated with the Laurentide ice sheet exists in such features as the Channelled 


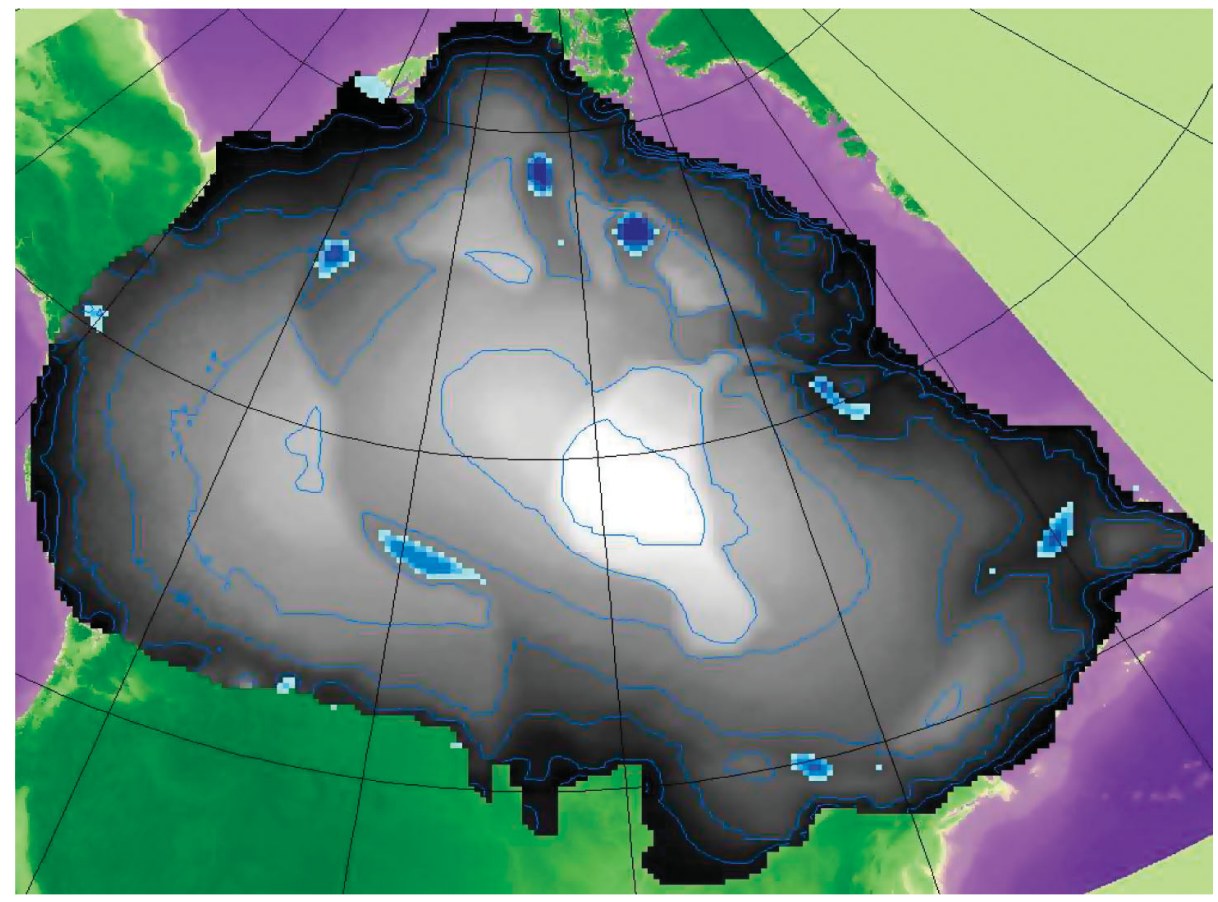

Figure 8. Some subglacial lake predictions for the Laurentide ice sheet at the LGM. Hydraulic potential surface in grey (and contoured), from which local minima are 'flooded', forming the basis of a prediction of subglacial lakes, marked in blue. This represents one of the 12 runs conducted and was computed using: bed elevation with a $10 \mathrm{~km}$ grid from GTOPO and IBACO datasets; ice surface elevation derived from the CLIMAP reconstruction, and with an effective pressure of 50 bar over the Canadian Shield and 1 bar elsewhere. See text for further description. Note that some of the lakes occur at the jump in hydraulic potential at the Shield boundary, apparent as the sharp grey-to-white transition to the north and west of Hudson Bay.

Scablands (Bretz 1923), and in giant meltwater channels on Baffin Island (Kleman et al. 2001). However, the subglacial terrain of the former Laurentide ice sheet is relatively flat, and the presently existing large lakes (the Great Lakes, Great Bear Lake, Great Slave Lake) are the best candidates for large former subglacial lakes. It is likely that their floods would have been large scale, with outlet discharge direct to the North Atlantic or to the Gulf of Mexico. One reason for supposing that these lakes also existed subglacially is that their existence is closely related to the border between exposed crystalline basement rock and tillcovered sedimentary rock (Clark \& Walder 1994; figure 4). This dramatic association suggests that the transition between the two bed types was instrumental in excavating the lakes, and the obvious mechanism to do this would be associated with a transition from low basal water pressure upstream to high basal water pressure downstream. The consequence of this for basal sliding is to cause a change in basal stress at the bed, and consequent enhanced longitudinal stress. That such enhanced stresses should cause enhanced excavation seems plausible. In addition, the effect of such a basal water pressure jump would be to cause a damming effect because of the associated jump in 


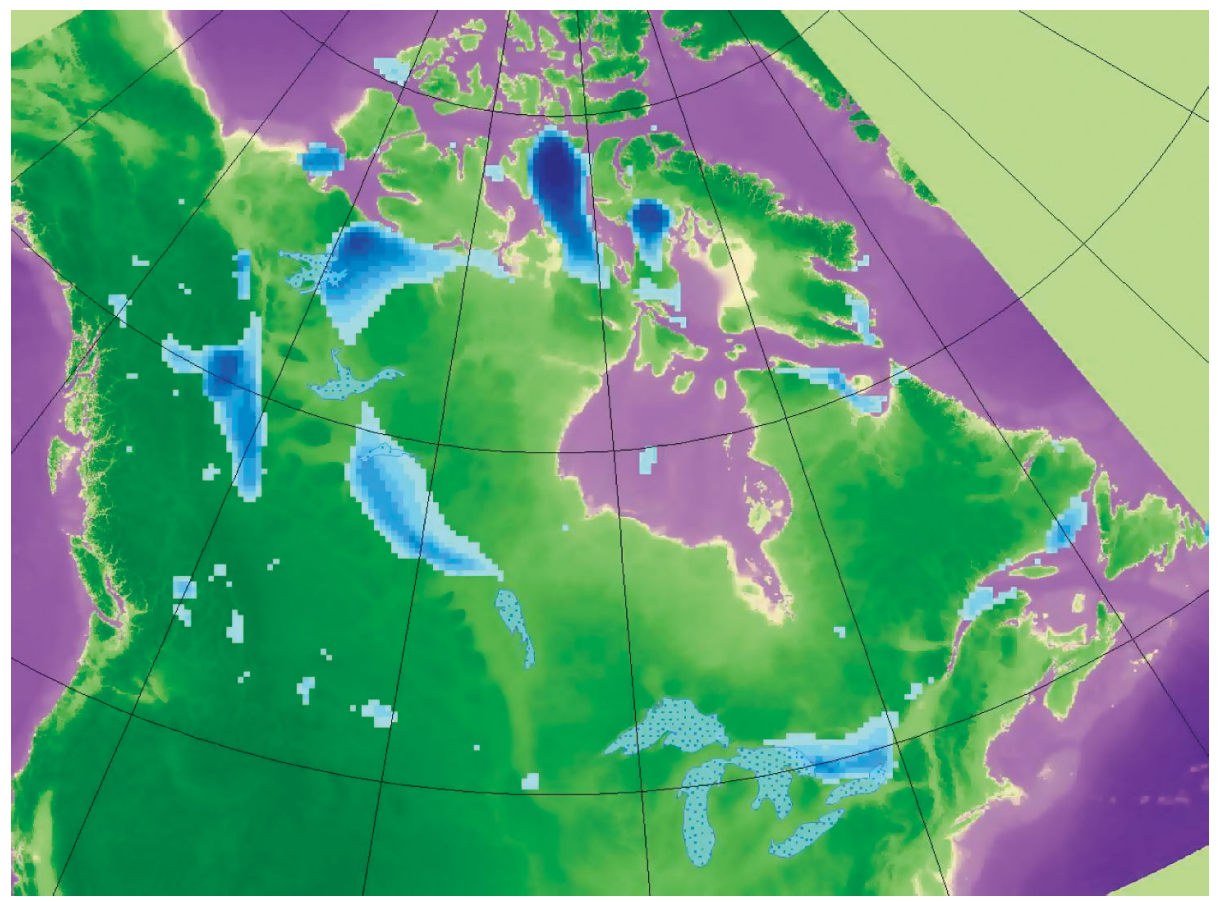

Figure 9. A 'likelihood map' of subglacial lakes of the Laurentide ice sheet. Darkness of blue approximates increased likelihood of a subglacial lake in that position, according to the runs conducted. Note that these are not lakes predicted at an instant in time, but are an amalgam of subglacial lake predictions from computations made for the 12 runs with varying boundary conditions; with a CLIMAP, ICE-5G and Dyke \& Prest (1987) ice sheet elevation and geometry: with ice sheets at half these thicknesses, and with varying effective pressures between the Canadian Shield and other areas. Existing large lakes are also shown (stippled blue) as these likely housed subglacial lakes, but do not form part of our analysis. See text for further explanation.

the hydraulic head, which might be expected to lead to lake formation. Yet, very little is known about subglacial drainage under ice sheets, and there may be many surprises in store.

For the Laurentide ice sheet at the last glacial maximum (LGM), we have explored likely locations where water could pond to produce subglacial lakes. Using a digital elevation model of the current land and seafloor surface and elevation models of ice surface topography, we computed three-dimensional surfaces representing the hydraulic potential at the ice sheet bed, measured in pascals. We make the assumption that the ice sheet was wholly warm-based and that basal melting was uniformly spread. Meltwater should follow the maximum gradient of the hydraulic potential surface, and in locations of local minima in this surface, water should pond to accumulate as a subglacial lake. Meltwater routing algorithms within a GIS were used, and local minima in the hydraulic potential surface were 'flooded' until the lip was reached. The area of flooding at such locations becomes a prediction for subglacial lake position, and the depression of the local minima below the general surrounding surface we take as a guide to the likelihood of ponding in this location. Figure 8 displays predicted lakes for one experiment. 
Given that lake prediction is sensitive to ice surface elevation and slope, and that we do not know this very well for a palaeo-ice sheet, we assessed the sensitivity of prediction by varying the ice surface. Three ice sheet geometries were used: the single-domed CLIMAP (1976) and Peltier's (2004) ICE-5G and our own multi-domed rendition approximating to Dyke \& Prest (1987). These cover a range from single to multi-domed geometries and variation in thickness. Predictions were also computed for half-thickness versions of these ice sheets to assess sensitivity to lower-sloped and thinner ice sheets, a crude proxy for ice sheets during retreat. Three further experiments were run using different boundary conditions of effective pressure. The first assumed that effective pressure was uniform across the ice sheet bed with water pressure equalling ice overburden pressure. The second and third runs used varying effective pressures. For the area of the hard-bedded Canadian Shield, we presume subglacial drainage was predominantly by R-channels, and for the softer geologies beyond the Shield, drainage is presumed to be predominantly in canals within sediment (cf. Clark \& Walder 1994). According to Walder \& Fowler (1994), the effect of different drainage styles on effective pressure is to produce significantly higher effective pressures over the Shield. We conducted runs with a 1-20 and 1-50 bar difference between non-shield and shield areas, respectively. Lake predictions were made for each of the 12 different sets of boundary conditions as outlined above. Figure 8 is an example of one of these outputs. We note that we have not accounted for isostatic depression of the bed and the effect this would have on basal topography, and that predictions are based solely on hydraulic potential, so in no way does this allow for dynamic changes to drainage or the ice sheet surface, as drainage or indeed subglacial lakes evolve.

In general, the ICE-5G ice sheet produced the most abundant lakes, which is surprising given that it is the thickest of the ice sheets and hence has steeper surface slopes to drive basal water out. It seems to be its geometry that produces this effect, with the main ice dome in Keewatin, over Yellowknife. As expected, the halfthickness ice sheets produced more subglacial lakes due to the lower surface slopes, which implies lake occurrence should be more prolific during build-up and ice retreat, compared to the LGM. Introduction of different effective pressures for the Shield and non-Shield areas created a jump in hydraulic potential at the Shield boundary, which in places, where ice surface slopes were favourable, yielded many lake predictions. Such lakes are clearly evident in figure 8. It is apparent from the different runs that certain locations preferentially yielded subglacial lakes, and figure 9 is an attempt to represent this by presenting an amalgam of lake predictions from all 12 cases. In summary, lakes are predicted to occur in bed depressions that are deep enough in relation to ice surface slopes above them, and in locations whereby the hydraulic jump at the Shield boundary and its interaction with ice surface slope, traps water. Our representation of bed topography did not include the bathymetry of the major Canadian lakes systems (Great Bear, Slave, and the Great Lakes), and this is why they have not appeared as predicted subglacial lakes. However, as these are mostly deep lakes, it is sensible to presume that they also had a high potential for accommodating subglacial lakes. Lake Winnipeg might be an exception to this as it approximates a large puddle.

The suggestion that Laurentide lakes might have a short, millennial time scale for flooding has an intriguing possible consequence concerning Dansgaard-Oeschger events (Dansgaard et al. 1993; Bond et al. 1997, 1999), as they provide a 
perturbation in freshwater flux to the North Atlantic (Ganopolski \& Rahmstorf 2001; Rahmstorf 2002), which is thought to be the cause of these events. In order for the theory to provide a suitable discharge and periodicity, we appear to need to have peak fluxes of the order of $0.1 \mathrm{~Sv}\left(10^{5} \mathrm{~m}^{3} \mathrm{~s}^{-1}\right)$, and that the flood periodicity be of the order of 1500 years. We see that the present flood theory can fit both these requirements (of order of magnitude).

Dansgaard-Oeschger events appear to have ceased at the end of the last ice age, although the 8200 year cooling event is thought to be associated with a massive discharge of the pro-glacial Lake Agassiz into the Hudson Strait (Clarke et al. 2004), but Bond et al. (1999) have suggested that pale imitations have continued into the Holocene. In particular, they suggested that the Little Ice Age between 1500 and 1800 might have been another event of the same type. If this was due to a perturbation in ocean circulation, then, following the logic of our thesis, we would suppose that such weaker climatic disturbances were driven either by floods from Antarctica, which may have rapid impact on Northern Hemisphere climate (Knorr \& Lohmann 2003; Weaver et al. 2003; Richardson et al. 2005), or by floods from below Greenland. Lakes below the Greenland ice sheet have not been identified, but it is plausible that they exist, given inferred basal melt conditions (Fahnestock et al. 2001; Dahl-Jensen et al. 2003).

We thank Duncan Wingham for several illuminating conversations. G.W.E. thanks W. H. R. Evatt for financial support. A.C.F. thanks the University of Limerick for their continued support of his research. C.D.C. thanks Monica Winsborrow for sharing her digital data of the Laurentide Ice Sheet.

\section{References}

Alley, R. B., Mayewski, P. A., Sowers, T., Stuiver, M., Taylor, K. C. \& Clark, P. U. 1997 Holocene climatic instability: a prominent, widespread event 8200 years ago. Geology 25, 483-486. (doi:10.1130/0091-7613(1997)025<0483:HCIAPW > 2.3.CO;2)

Baker, V. R. 2001 Water and the martian landscape. Nature 412, 228-236. (doi:10.1038/35084172)

Baker, V. R. \& Milton, D. J. 1974 Erosion by catastrophic floods on Mars and Earth. Icarus 23, 27-41. (doi:10.1016/0019-1035(74)90101-8)

Björnsson, H. 1974 Explanation of jökulhlaups from Grímsvötn, Vatnajökull, Iceland. Jökull 24, $1-26$.

Björnsson, H. 1988 Hydrology of ice caps in volcanic regions. Reykjavik: Societas Scientarium Islandica, University of Iceland.

Björnsson, H. 1992 Jökulhlaups in Iceland: prediction, characteristics and simulation. Ann. Glaciol. 16, 95-106.

Bond, G. et al. 1992 Evidence for massive discharges of icebergs into the North Atlantic ocean during the last glacial period. Nature 360, 245-249. (doi:10.1038/360245a0)

Bond, G. C. et al. 1997 A pervasive millennial-scale cycle in North Atlantic Holocene and glacial climates. Science 278, 1257-1266. (doi:10.1126/science.278.5341.1257)

Bond, G. C., Showers, W., Elliott, M., Evans, M., Lotti, R., Hajdas, I., Bonani, G. \& Johnson, S. 1999 The North Atlantic's 1-2 kyr climate rhythm: relation to Heinrich events, Dansgaard/Oeschger cycles and little ice age. In Mechanisms of global climate change (ed. P. U. Clark, R. S. Webb \& L. D. Keigwin) Geophysical monographs, vol. 112, pp. 35-58. Washington, DC: American Geophysical Union.

Bretz, J. H. 1923 The channeled Scablands of the Columbia Plateau. J. Geol. 31, 617-649.

Bretz, J. H. 1969 The Lake Missoula floods and the Channeled Scabland. J. Geol. 77, 505-543. 
Chapman, M. G., Guðmundsson, M. T., Russell, A. J. \& Hare, T. M. 2003 Possible Juventae Chasma sub-ice volcanic eruptions and Maja Valles ice outburst floods, Mars: implications of Mars Global Surveyor crater densities, geomorphology, and topography. J. Geophys. Res. 108 art. no. 5113.

Clark, P. U. \& Walder, J. S. 1994 Subglacial drainage, eskers, and deforming beds beneath the Laurentide and Eurasian ice sheets. Geol. Soc. Am. Bull. 106, 304-314. (doi:10.1130/00167606(1994)106<0304:SDEADB > 2.3.CO;2)

Clarke, G. K. C. 1982 Glacier outburst floods from 'Hazard Lake', Yukon Territory, and the problem of flood magnitude prediction. J. Glaciol. 28, 3-21.

Clarke, G. K. C. 2003 Hydraulics of subglacial outburst floods: new insights from the Spring-Hutter formulation. J. Glaciol. 49, 299-313.

Clarke, G. K. C., Leverington, D. W., Teller, J. T. \& Dyke, A. S. 2004 Paleohydraulics of the last outburst flood from glacial Lake Agassiz and the 8200 BP cold event. Quat. Sci. Rev. 23, 389-407. (doi:10.1016/j.quascirev.2003.06.004)

Clarke, G. K. C., Leverington, D. W., Teller, J. T., Dyke, A. S. \& Marshall, S. J. 2005 Fresh arguments against the Shaw megaflood hypothesis. A reply to comments by David Sharpe on 'Paleohydraulics of the last outburst flood from glacial Lake Agassiz and the 8200 BP cold event'. Quat. Sci. Rev. 24, 1533-1541. (doi:10.1016/j.quascirev.2004.12.003)

CLIMAP Project Members 1976 The surface of the Ice-Age Earth. Science 191, 1131-1137.

Dahl-Jensen, D., Gundestrup, N., Gogineni, S. P. \& Miller, H. 2003 Basal melt at NorthGRIP modeled from borehole, ice-core and radio-echo sounder observations. Ann. Glaciol. 37, $207-212$.

Dansgaard, W. et al. 1993 Evidence for general instability of past climate from a 250-kyr ice-core record. Nature 364, 218-220. (doi:10.1038/364218a0)

Denton, G. H. \& Sugden, D. E. 2005 Meltwater features that suggest Miocene ice-sheet overriding of the Transantarctic Mountains in Victoria Land, Antarctica. Geogr. Ann. 87A, 67-85. (doi:10. 1111/j.0435-3676.2005.00245.x)

Dyke, A. S. \& Prest, V. K. 1987 Late Wisconsinan and Holocene history of the Laurentide Ice Sheet. Geogr. Phys. Quat. 41, 237-263.

Evatt, G. W. In preparation. Jökulhlaups and sub-glacial floods. D.Phil. thesis.

Fahnestock, M., Abdalati, W., Joughin, I., Brozena, J. \& Gogineni, P. 2001 High geothermal flow, basal melt, and the origin of rapid flow in Central Greenland. Science 294, 2338-2342. (doi:10. 1126/science.1065370)

Fowler, A. C. 1999 Breaking the seal at Grímsvötn. J. Glaciol. 45, 506-516.

Fowler, A. C. \& Larson, D. A. 1978 On the flow of polythermal glaciers, part I: model and preliminary analysis. Proc. R. Soc. A 363, 217-242.

Ganopolski, A. \& Rahmstorf, S. 2001 Rapid changes of glacial climate simulated in a coupled climate model. Nature 409, 153-158. (doi:10.1038/35051500)

Goodwin, I. D. 1988 The nature and origin of a jökulhlaup near Casey Station, Antarctica. J. Glaciol. 34, 95-101.

Guðmundsson, M. T., Sigmundsson, F. \& Björnsson, H. 1997 Ice-volcano interaction of the 1996 Gjálp subglacial eruption, Vatnajökull, Iceland. Nature 389, 954-957. (doi:10.1038/ 40122)

Guðmundsson, M. T., Sigmundsson, F., Björnsson, H. \& Högnadóttir, T. 2004 The 1996 eruption at Gjálp, Vatnajökull ice cap, Iceland: efficiency of heat transfer, ice deformation and subglacial water pressure. Bull. Volcanol. 66, 46-65. (doi:10.1007/s00445-003-0295-9)

Hall, S. J. 1815 On the revolutions of the Earth's surface. Trans. R. Soc. Edinb. 7, 139-212.

Heinrich, H. 1988 Origin and consequences of cyclic ice rafting in the Northeast Atlantic Ocean during the past 130000 years. Quat. Res. 29, 142-152. (doi:10.1016/0033-5894(88)90057-9)

Hindmarsh, R. C. A. 2001 Notes on basic glaciological computational methods and algorithms. In Continuum mechanics and applications in geophysics and the environment (ed. B. Straughan, R. Greve, H. Ehrentraut \& Y. Wang), pp. 222-249. Berlin: Springer. 
Holland, D. M. \& Jenkins, A. 1999 Modeling thermodynamic ice-ocean interactions at the base of an ice shelf. J. Phys. Oceanogr. 29, 1787-1800. (doi:10.1175/1520-0485(1999)029< 1787:MTIOIA > 2.0.CO;2)

Howell, P. D. 1994. Extensional thin layer flows. D.Phil. thesis, University of Oxford.

Jenkins, A. 1991 A one-dimensional model of ice shelf-ocean interaction. J. Geophys. Res. 96, $20671-20677$.

Johnsen, S. J. et al. 1992 Irregular glacial interstadials recorded in a new Greenland ice core. Nature 359, 311-313. (doi:10.1038/359311a0)

Kleman, J., Marchant, D. \& Borgström, I. 2001 Geomorphic evidence for late glacial ice dynamics on Southern Baffin Island and in Outer Hudson Strait, Nunavut, Canada. Arct. Antarc. Alp. Res. 33, 249-257.

Knorr, G. \& Lohmann, G. 2003 Southern Ocean origin for the resumption of Atlantic thermohaline circulation during deglaciation. Nature 424, 532-536. (doi:10.1038/nature01855)

Lythe, M. B., Vaughan, D. G. \& the BEDMAP Consortium 2001 BEDMAP: a new ice thickness and subglacial topographic model of Antarctica. J. Geophys. Res. 106, 11 335-11 352. (doi:10. 1029/2000JB900449)

MacAyeal, D. R. 1993 Binge/purge oscillations of the Laurentide ice sheet as a cause of the North Atlantic's Heinrich events. Paleoceanography 8, 775-784.

Ng, F. S. L. 1998. Mathematical modelling of subglacial drainage and erosion. D.Phil. thesis, University of Oxford.

Nye, J. F. 1951 The flow of glaciers and ice-sheets as a problem in plasticity. Proc. R. Soc. A 207, $554-572$.

Nye, J. F. 1953 The flow law of ice from measurements in glacier tunnels, laboratory experiments and the Jungfraufirn borehole experiment. Proc. R. Soc. A 219, 477-489.

Nye, J. F. 1976 Water flow in glaciers: jökulhlaups, tunnels, and veins. J. Glaciol. 17, 181-207.

Paterson, W. S. B. 1994 The physics of glaciers, 3rd edn. Oxford, UK: Pergamon Press.

Peltier, W. R. 2004 Global glacial isostasy and the surface of the ice age Earth: the ICE-5G (VM2) model and GRACE. Annu. Rev. Earth Planet. Sci. 32, 111-149. (doi:10.1146/annurev.earth.32. 082503.144359)

Rahmstorf, S. 2002 Ocean circulation and climate during the past 120000 years. Nature 419, 207-214. (doi:10.1038/nature01090)

Richardson, G., Wadley, M. R., Heywood, K. J., Stevens, D. P. \& Banks, H. T. 2005 Short-term climate response to a freshwater pulse in the Southern Ocean. Geophys. Res. Lett. 32, L03 702. (doi:10.1029/2004GL021586)

Roberts, M. J. 2005 Jökulhlaups: a reassessment of floodwater flow through glaciers. Rev. Geophys. 43, RG1002. (doi:10.1029/2003RG000147)

Röthlisberger, H. 1972 Water pressure in intra- and subglacial channels. J. Glaciol. 11, 177-203.

Shaw, J. 1983 Drumlin formation related to inverted meltwater erosional marks. J. Glaciol. 29, 461-479.

Shaw, J., Kvill, D. \& Rains, B. 1989 Drumlins and catastrophic subglacial floods. Sediment. Geol. 62, 177-202. (doi:10.1016/0037-0738(89)90114-0)

Siegert, M. J. 2005 Lakes beneath the ice sheet: the occurrence, analysis, and future exploration of Lake Vostok and other Antarctic subglacial lakes. Annu. Rev. Earth Planet. Sci. 33, 215-245. (doi:10.1146/annurev.earth.33.092203.122725)

Siegert, M. J., Dowdeswell, J. A., Gorman, M. R. \& McIntyre, N. F. 1996 An inventory of Antarctic sub-glacial lakes. Antarc. Sci. 8, 281-286.

Siegert, M. J., Ellis-Evans, J. C., Tranter, M., Mayer, C., Petit, J.-R., Salamatin, A. \& Priscu, J. C. 2001 Physical, chemical and biological processes in Lake Vostok and other Antarctic subglacial lakes. Nature 414, 603-608. (doi:10.1038/414603a)

Spring, U. \& Hutter, K. 1981 Numerical studies of jökulhlaups. Cold Reg. Sci. Technol. 4, 227-244. (doi:10.1016/0165-232X(81)90006-9)

Spring, U. \& Hutter, K. 1982 Conduit flow of a fluid through its solid phase and its application to intraglacial channel flow. Int. J. Eng. Sci. 20, 327-363. (doi:10.1016/0020-7225(82)90029-5) 
Stocker, T. F. \& Wright, D. G. 1991 Rapid transitions of the ocean's deep circulation induced by changes in surface water fluxes. Nature 351, 729-732. (doi:10.1038/351729a0)

Sugden, D. \& Denton, G. 2004 Cenozoic landscape evolution of the Convoy Range to Mackay Glacier area, Transantarctic Mountains: onshore to offshore synthesis. GSA Bull. 116, 840-857.

Szekely, J., Evans, J. W. \& Sohn, H. Y. 1976 Gas-solid reactions. New York, NY: Academic Press.

Taylor, K. C., Lamorey, G. W., Doyle, G. A., Alley, R. B., Grootes, P. M., Mayewski, P. A., White, J. W. C. \& Barlow, L. K. 1993 The 'flickering switch' of late Pleistocene climate change. Nature 361, 432-436. (doi:10.1038/361432a0)

Tikku, A. A., Bell, R. E., Studinger, M., Clarke, G. K. C., Tabacco, I. \& Ferraccioli, F. 2005 Influx of meltwater to subglacial Lake Concordia, East Antarctica. J. Glaciol. 51, 96-104.

Van der Veen, C. J. 1999 Fundamentals of glacier dynamics. Rotterdam: A.A. Balkema.

Walder, J. S. \& Fowler, A. 1994 Channelised subglacial drainage over a deformable bed. J. Glaciol. 40, $3-15$.

Weaver, A. J., Saenko, O. A., Clark, P. U. \& Mitrovica, J. X. 2003 Meltwater pulse 1A from Antarctica as a trigger of the Bølling-Allerød warm interval. Science 299, 1709-1713. (doi:10. 1126/science.1081002)

Wingham, D. J., Siegert, M. J., Shepherd, A. P. \& Muir, A. S. 2006 Rapid discharge connects Antarctic subglacial lakes. Nature 440, 1033-1036. 